\title{
(ind \\ Method development and validation of Bio Flavanoid- Morin Hydrate by RP-HPLC in Human Plasma
}

\author{
Mani Rupesh Kumar ${ }^{1}$, Selvadurai Muralidharan² \\ ${ }^{1}$ Unit of Pharmacology, Faculty of Pharmacy, AIMST University, Semeling, Bedong 08100, Kedah, Malaysia \\ ${ }^{2}$ Unit of Pharmaceutical chemistry, Faculty of Pharmacy, AIMST University, Semeling, Bedong 08100, \\ Kedah, Malaysia
}

\begin{abstract}
Objective: To develop a new, rapid and sensitive RP-HPLC method for the estimation of morin in human plasma by protein precipitation method (PPT) because of more recovery. Method: Chromatographic separation was carried out on a reverse phase $\mathrm{C}_{18}$ column using mixture of $10 \mathrm{mM}$ potassium dihydrogen phosphate $(\mathrm{pH} 5.0)$ and acetonitrile $(60: 40, \mathrm{v} / \mathrm{v})$ at a flow rate of $1.0 \mathrm{ml} / \mathrm{min}$ with UV detection at $260 \mathrm{~nm}$. The method was validated and found to be linear in the range of $100-500$ $\mathrm{ng} / \mathrm{ml}$. Results: The degree of reproducibility of the results obtained as a result of small deliberate variations in the method parameters and by changing analytical operator has proven that the method is robust and rugged. The present method is suitable in terms of precise, accurate and specific during the study. Conclusion: The simplicity of the method allows for application in laboratories that lack sophisticated analytical instruments which are complicated, costly and time consuming rather than a simple HPLC-UV method. The present method was successfully applied for bioavailability and bioequivalence studies and pharmacokinetic profile studies.
\end{abstract}

Key words: Application to PK profile studies, Method development, Morin and validation.

\section{INTRODUCTION}

Flavonoids are a large class of compounds consisted of A and $\mathrm{C}$ rings of benzo-1-pyran-4-quinone and a Bring, and further sub classified as flavones (basic structure), flavonols (having a hydroxyl group at the 3-position), isoflavones (B ring binds to the 3 -position), flavanones ( $2-3$ bond is saturated), and catechins (C-ring is 1-pyran), chalcones

\begin{tabular}{|c|l|}
\hline \multicolumn{2}{|c|}{ Access this article online } \\
\hline \multirow{2}{*}{ Journal Sponsor } & \multicolumn{1}{|l|}{ Website: } \\
www.jyoungpharm.org \\
\hline \multirow{2}{*}{ www.phcog net } & \\
\cline { 2 - 2 } & DOI: \\
& $10.5530 /$ jyp.2015.3.9 \\
\hline
\end{tabular}

(C-ring is opened), and anthocyanidins (C-ringis 1-pyran, and 1-2 and 3-4 bonds are unsaturated). It has many substituents such as hydroxyl and/or methoxyl groups. Flavones can prevent many diseases including cancers through antioxidative action and/or the modulation of several enzyme functions. Example, they may reduce coronary heart disease mortality ${ }^{1}$ by suppressing the oxidation of low-density lipoprotein. ${ }^{2}$ Anticarcinogenic activity of flavones is expressed by their agonism and/ or antagonism of carcinogenesis-related receptors such as epidermal growth factor, ${ }^{3}$ arylhydrocarbon receptor ${ }^{4}$ and estrogen receptor $\beta .{ }^{5}$ The secretion of cytokines, ${ }^{6-8}$ and expression of protein kinases in tumor cell proliferation ${ }^{9,10}$ could be modulated by polyphenols.

\footnotetext{
*Address for correspondence:

Dr. Selvadurai Muralidharan, Unit of Pharmaceutical chemistry, Faculty of Pharmacy, Semeling-08100, Bedong, Kedah, Malaysia. E-mail:murali23pharm@hotmail.com
} 


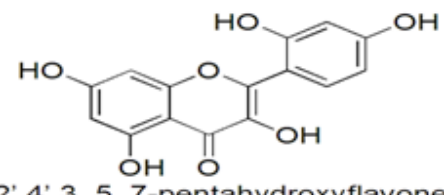

$2^{\prime}, 4^{\prime}, 3,5,7$-penta
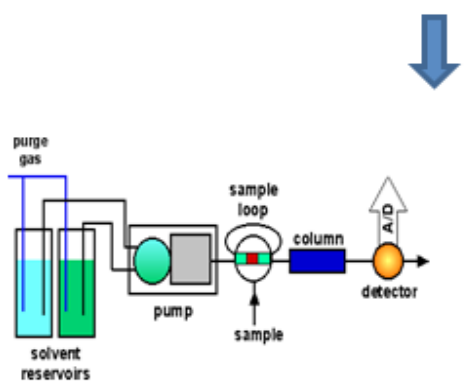

Mobile phase: $10 \mathrm{mM}$ potassium dihydrogen phosphate $(\mathrm{pH} 5.0)$ and acetonitrile $(60: 40, \mathrm{v} / \mathrm{v})$ at a flow rate of $1.0 \mathrm{ml} / \mathrm{min}$ with UV detection at $260 \mathrm{~nm}$. Run time 5 mins.

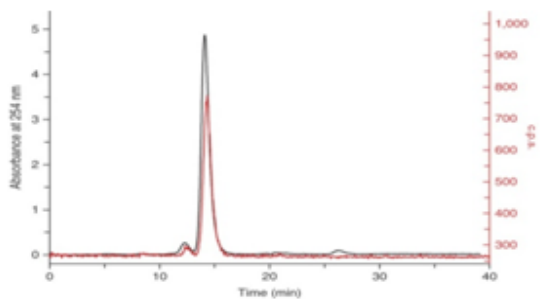

Graphical Abstract

Morin is typical representative of flavonoids which bears most of their physiological functions. Hence, it is of interest to develop simple, accurate and precise method for the determination of morin in human plasma. So far, only limited analytical methods such as thin-layer chromatography, ${ }^{11}$ gas chromatography, ${ }^{12}$ capillary electrophoresis, ${ }^{13-17}$ electrochemical measurements, ${ }^{18}$ high-performance liquid chromatography (HPLC). HPLC method was most commonly used to separate and analyse flavonoids because of its more accurate and precision. As a reference method we used modified RP-HPLC determination of morin based on extraction of morin from human plasma samples with trichloroacetic acid. Literature survey reveals that no simple, rapid and reproducible methods so far reported for the development of morin in human plasma. The objective of the present investigation was to develop a new, rapid and sensitive RP-HPLC method for the estimation of morin in human plasma. In the present study, a more sensitive, and precise method was to be developed and applied to the pharmacokinetic study.

\section{EXPERIMENTAL}

\section{Materials and reagents}

Morin Hydrate (99.65\%) reference standard was procured from Sigma Aldrich Pvt Ltd. (Mumbai, India). Acetonitrile
(HPLC grade) was obtained from Merck, Germany. trichloro acetic acid was obtained from Systerm Malaysia. Methanol obtained from QREC and HPLC grade water was used throughout the study.

\section{Equipment}

HPLC chromatographic separation was performed on a Shimadzu liquid chromatographic system equipped with a LC-20AD solvent delivery system (pump), SPD-20A photo diode array detector, and SIL-20ACHT injector. LC solution version 1.25 was applied for data collecting and processing (Shimadzu, Japan).

\section{Preparation of the calibration standards and quality control (QC) samples}

The stock solution of morin was prepared in methanol at a concentration of $1.0 \mathrm{mg} / \mathrm{ml}$. The working solution of $100.0 \mathrm{ng} / \mathrm{ml}$ was prepared by appropriately diluting the stock solution of morin. Morin working solution was used to prepare the spiking stock solutions for construction of six-point calibration curve $(100.0-500.0 \mathrm{ng} / \mathrm{ml})$ and QC samples at three different levels (100.0, 300.0, $500.0 \mathrm{ng} /$ $\mathrm{ml})$. All the stock solutions were refrigerated $\left(2-8^{\circ} \mathrm{C}\right)$ when not in use. Calibration standards and QC samples were prepared in bulk by spiking $250.0 \mu \mathrm{l}$ of respective spiking stock solutions to $250.0 \mu \mathrm{l}$ of human plasma and then 
aliquoted. These were stored at $-70^{\circ} \mathrm{C}$ until analysis.

\section{Sample preparation for analysis}

At the time of analysis, the plasma samples were removed from the deep freezer and kept in the room temperature and allowed to thaw. A volume of $500 \mu \mathrm{l}$ of sample was pipetted into $2.0 \mathrm{ml}$ centrifuge tube and $250 \mu \mathrm{l}$ of precipitating agent (10\% trichloroacetic acid) was added. The resulting solution was vortexed for 2 minutes and centrifuged at $5000 \mathrm{RPM}$ for $5 \mathrm{~min} .20 .0 \mu \mathrm{l}$ of the sample was injected to the HPLC system for analysis. All the procedures were performed at room temperature.

\section{Chromatographic conditions}

The samples were chromatographed on a Princeton SPHER C $_{18}(250 \times 4.6 \mathrm{~mm}$ i.d., $5 \mathrm{~m})$ column with a flow rate of $0.9 \mathrm{ml} / \mathrm{min}$. The mobile phase used was acetonitrile potassium dihydrogen phosphate $(60: 40 \% \mathrm{v} / \mathrm{v})$. potassium dihydrogen phosphate used was $20 \mathrm{mM}$ solution in water with $\mathrm{pH}$ being adjusted to 5.0 with orthophosphoric acid solution. The injection volume was $20.0 \mu \mathrm{l}$. The UV-visible detector was set at $260 \mathrm{~nm}$.

\section{Validation}

The method has been validated ${ }^{19}$ for selectivity, sensitivity, recovery, linearity, precision, accuracy and stability.

\section{Selectivity}

The selectivity of the method was evaluated by comparing the chromatograms obtained from the sample containing morin standard with those obtained from blank samples.

\section{Sensitivity}

Sensitivity was determined in terms of LLOQ (Lower Limit of Quantification) where the response of LLOQ was at least five times greater than the response of interference in blank matrix at the retention time or mass transitions of the analyte.

\section{Linearity}

For linearity, different concentrations of standard solution were prepared to contain $100.0 \mathrm{ng} \mathrm{m} \mathrm{L}$ Lo $^{-1} 500.0 \mathrm{ng} / \mathrm{ml}$ of morin. These solutions were analyzed and the peak areas and response factors were calculated. The calibration curve was plotted using response factor vs. concentration of the standard solutions. Standard curve fitting was determined by applying the simplest model that adequately describes the concentration-response relationship using appropriate weighting and statistical tests for goodness of fit.

\section{Precision and Accuracy}

Intraday and interday precision method was used to determine the precision. The intra-assay precision and accuracy was calculated for five replicates at each Lower Limit of Quantification (LLOQ), Low Quality Control (LQC), Middle Quality Control (MQC) and High Quality Control (HQC) levels, each on the same analytical run, and inter-assay precision and accuracy was calculated after repeated analysis in three different analytical runs.

\section{Stability Studies}

Stability study was carried out at room temperature stock solution stability, refrigerated stock solution stability, freeze thaw stability, short term stability and long term stability were determined. Room temperature stock solution stability was carried out at 0,3 and 8 hours by injecting four replicates of prepared stock dilutions of morin equivalent to middle quality control sample concentration and the stock dilution equivalent to the working concentration. Refrigerated stock solution stability was determined at 7, 14 and 21 days by injecting 4 replicates of prepared stock dilutions of the analyze equivalent to the middle quality control sample concentration. The stability studies of plasma samples spiked with morin were subjected to three freeze - thaw cycles, short term stability at room temperature for $3 \mathrm{~h}$ and long term stability at $-70^{\circ} \mathrm{C}$ over four weeks. Stability of standard solutions was performed at room temperature over $6 \mathrm{~h}$ and after freezing for four weeks has also been carried out. The stability of triplicate spiked human plasma samples following three freeze thaw cycles was analyzed. At room temperature for 1.00 to 3.00 $\mathrm{h}$ before extraction the stability of triplicate short term samples spiked with morin was investigated. The plasma samples for long term stability were stored in the freezer at $70^{\circ} \mathrm{C}$ until the time of study.

\section{RESULTS AND DISCUSSION}

\section{Selectivity}

No interfering endogenous compound peak was observed at the retention time of analyte. Under chromatographic conditions, the retention times of morin was $5.12 \mathrm{~min}$. Representative chromatograms of Lower Limit of Quantization (LLOQ) and one study sample containing morin are shown in Figure. 1 and 2 respectively. 


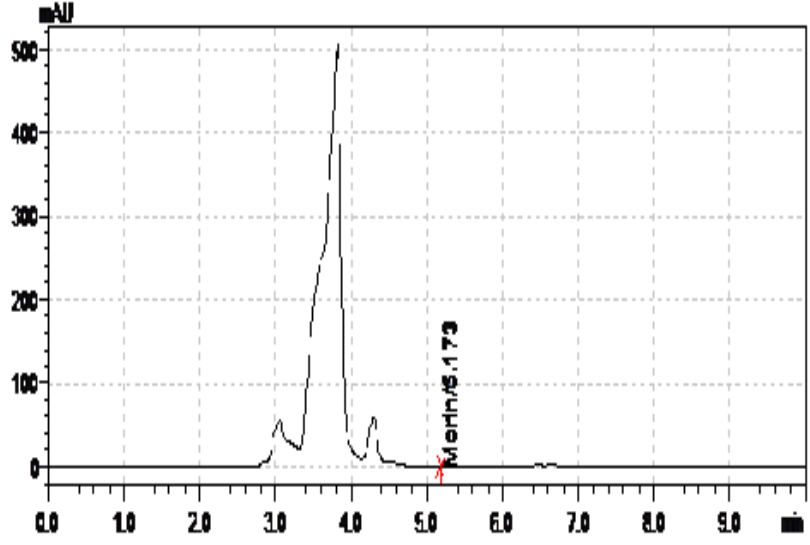

Figure 1: Typical chromatogram of blank plasma

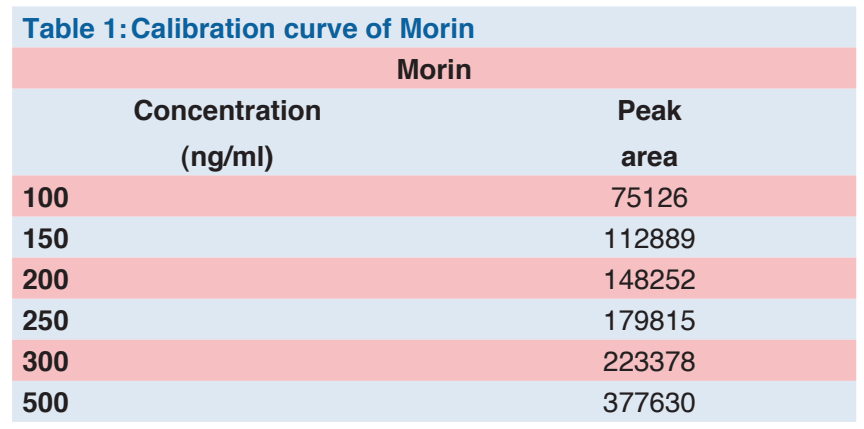

\section{Sensitivity}

The sensitivity of the experiment was carried out at LLOQ level. The average percentage deviation from the nominal concentration was less than $10 \%$.

\section{Linearity and Recovery studies}

The calibration curves were linear over the range of 100.0$500.0 \mathrm{ng} \mathrm{mL}-1$. The correlation coefficient was $>0.9996$. Calibration curve data of morin result shown in Table 1. Recovery studies presented in Table 2 Figure. 3.

\section{Precision and Accuracy}

Both intra-day and inter-day accuracy and precision of the method were determined by analysis of the control human

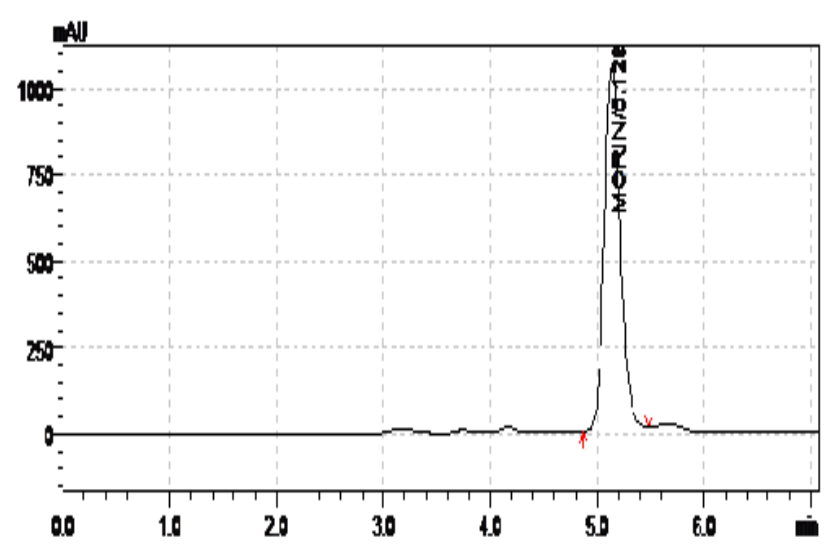

Figure 2: Typical chromatogram of standard solution

\begin{tabular}{|c|c|c|}
\hline \multicolumn{3}{|c|}{ Drug } \\
\hline & $\begin{array}{c}\text { Prepared } \\
\text { Concentration } \\
(\mathrm{ng} / \mathrm{ml})\end{array}$ & $\%$ Recovery \\
\hline \multirow{3}{*}{ Morin } & 100 & 89.56 \\
\hline & 300 & 90.52 \\
\hline & 500 & 91.02 \\
\hline
\end{tabular}

plasma spiked with morin at LLOQ, LQC, MQC and HQC. All QCs concentration was calculated using the calibration curve. The accuracy and precision of the method were described as a percentage bias and the percentage relative standard deviation, respectively Table 3 .

\section{Speed of Analysis}

The analysis is performed within $11 \mathrm{~min}$ in which $5 \mathrm{~min}$ for extraction of plasma and 6 min for chromatography Figure 4.

\section{System suitability}

System suitability test was performed daily before the run of analytical batch to check detector response to the analyze. Both the formulations were well tolerated by all

Table 3: Intraday and interday precision studies of Morin in human plasma

\begin{tabular}{|c|c|c|c|c|c|c|}
\hline & \multicolumn{3}{|c|}{ Intraday studies } & \multicolumn{3}{|c|}{ Interday studies } \\
\hline & 100 & $\begin{array}{c}300 \\
(\mathrm{ng} / \mathrm{ml})\end{array}$ & 500 & 100 & $\begin{array}{c}300 \\
(\mathrm{ng} / \mathrm{ml})\end{array}$ & 500 \\
\hline Mean & 98.7268 & 298.8793 & 499.0173 & 98.8039 & 298.7657 & 499.3013 \\
\hline SD & 0.811 & 0.346 & 0.263 & 0.691 & 0.786 & 0.33 \\
\hline$\% \mathrm{CV}$ & 0.822 & 0.116 & 0.052 & 0.699 & 0.263 & 0.066 \\
\hline \%Accuracy & 98.7 & 99.6 & 99.8 & 98.8 & 99.5 & 99.8 \\
\hline
\end{tabular}




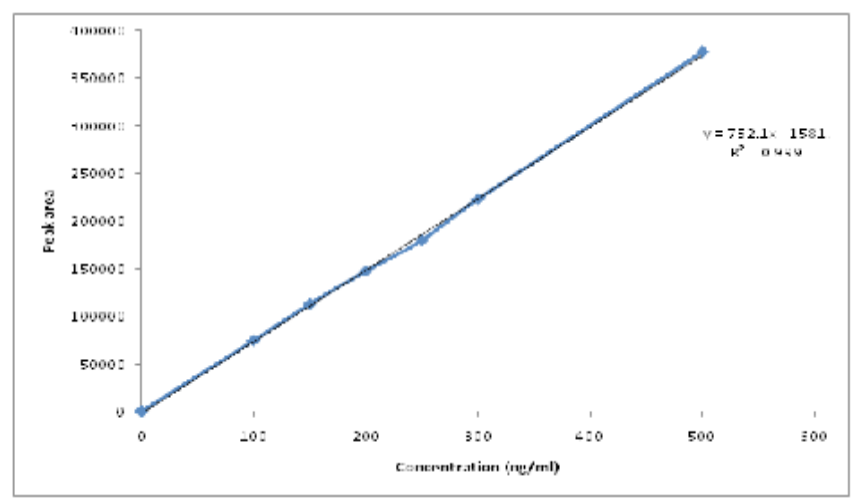

Figure 3: Calibration curve of Morin in blank human plasma

\begin{tabular}{lc|}
\hline \multicolumn{1}{|c|}{ Table 4: System suitability studies } & \\
\hline Parameters & Morin \\
\hline Theoretical plate/meter & 4985 \\
\hline Asymmetric factor & 0.91 \\
\hline LOD $(\mathrm{ng} / \mathrm{ml})$ & 50 \\
\hline LOQ $(\mathrm{ng} / \mathrm{ml})$ & 100 \\
\hline
\end{tabular}

the volunteers in both the phases of study Table 4 .

\section{Stability}

Analysis of the stock solution was performed at 100.0 $\mathrm{ng} / \mathrm{ml}$. After storage for 15 days at $2-8^{\circ} \mathrm{C}$ and at room temperature for $6 \mathrm{~h}$, more than $97.5 \%$ of morin remained unchanged, based on peak areas in comparison with freshly prepared solution of morin $(100.0 \mathrm{ng} / \mathrm{ml})$ This suggests that the morin in standard solution is stable for at least 15 days when stored at $2-8^{\circ} \mathrm{C}$ and for $6 \mathrm{~h}$ at room temperature.

Bench top stability of morin in plasma was investigated at LQC and HQC levels. This revealed that the morin in plasma was stable for at least $6 \mathrm{~h}$ at room temperature. It was confirmed that repeated freezing and thawing (three cycles) of plasma samples spiked with morin at LQC and HQC level did not affect the stability of morin Long term stability of the morin in plasma at $-70^{\circ} \mathrm{C}$ was also performed after 30 days of storage at LQC, HQC levels. The results of the stability studies are shown in Table 5. The above results indicated that the morin was stable in the studied conditions.

\section{CONCLUSION}

A simple and sensitive method for morin in human plasma

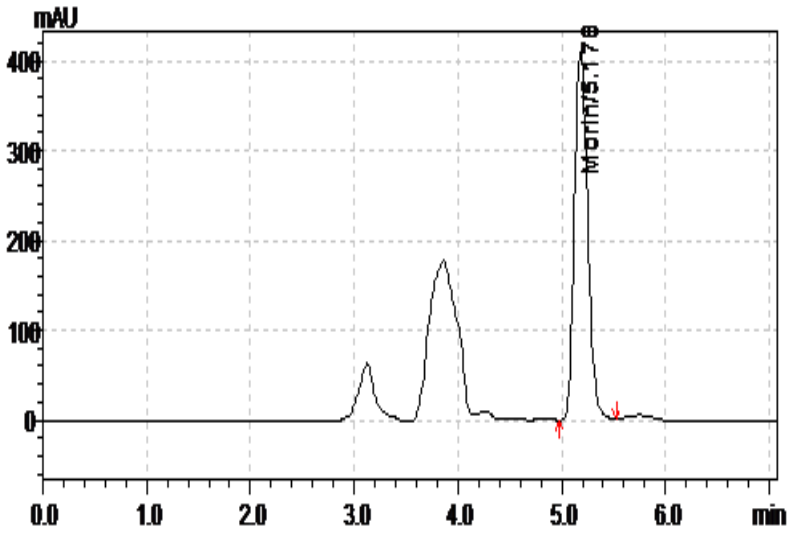

Figure 4: Typical chromatogram of spiked solution

\begin{tabular}{|c|c|c|}
\hline $\begin{array}{l}\text { Concentration } \\
(\mathrm{ng} / \mathrm{ml})(\mathrm{n}=6)\end{array}$ & $\begin{array}{l}\text { Concentration } \\
\text { found } \\
\text { (mean } \pm \text { S.D.) }(\mathrm{ng} / \\
\mathrm{ml})\end{array}$ & $\% \mathrm{CV}$ \\
\hline \multicolumn{3}{|c|}{ Short-term stability (1, 2, 3 h) } \\
\hline 100 & $99.85 \pm 0.43$ & 3.10 \\
\hline 500 & $498.63 \pm 1.25$ & 1.95 \\
\hline \multicolumn{3}{|c|}{ Long-term stability (4 weeks) } \\
\hline 100 & $98.96 \pm 1.04$ & 4.17 \\
\hline 500 & $498.75 \pm 1.15$ & 1.96 \\
\hline \multicolumn{3}{|l|}{ Stock Solution Stability } \\
\hline 100 & $99.54 \pm 0.97$ & 2.96 \\
\hline 500 & $499.63 \pm 1.24$ & 1.09 \\
\hline \multicolumn{3}{|c|}{ Freeze thaw Stability (3 Cycle) } \\
\hline 100 & $98.99 \pm 1.27$ & 3.87 \\
\hline 500 & $499.02 \pm 0.59$ & 2.12 \\
\hline \multicolumn{3}{|l|}{ Auto Sampler Stability } \\
\hline 100 & $99.52 \pm 0.85$ & 2.89 \\
\hline 500 & $499.97 \pm 0.49$ & 1.856 \\
\hline \multicolumn{3}{|c|}{ Stability of Morin in Plasma $\left(20^{\circ} \mathrm{C}\right)$} \\
\hline 100 & $99.63 \pm 0.75$ & 3.19 \\
\hline 500 & $499.67 \pm 1.07$ & 1.27 \\
\hline
\end{tabular}

was developed and validated as per FDA guidelines. This method offers significant advantages over those previously reported, in terms of improved sensitivity and selectivity, faster run time (6 min) and lower sample requirements. Hence, this method may be useful for single and multiple ascending dose studies in human subjects. The developed method has excellent sensitivity, reproducibility and specificity. The method has been successfully used to provide the bioavailability and bioequivalent study of morin in animal and human plasma. The developed assay showed acceptable precision, accuracy, linearity, stability, and specificity so applicable to clinical tool. 


\section{Highlights of Paper}

- Method was developed and validated as per FDA guidelines.

- The developed method has sensitivity and selectivity, faster run time (6 min) and lower sample requirements.

\section{Author Profile}

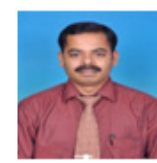

- Dr.S.Muralidharan has been completed M.Pharm and Ph.Din the Department of Pharmaceutical Analysis in Tamil Nadu Dr.MGRMedical University,India.Presently working as a Senior Lecturer in Faculty of Pharmacy, AIMST University, Malaysia.

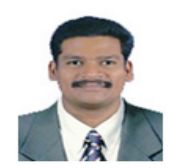

- Mr.M.Rupeshkumar completed M.Pharm in the Department of Pharmacology in JadavpurUniversity, India. Presently working as a Senior Lecturer in Faculty of Pharmacy, AIMST University, Malaysia.

\section{REFERENCES}

1. Hertog MGL, Kromhout D, Aravanis C, Blackburn H, Buzina R, Fidanza F, Giampaoli S, Jansen A, Menotti A, Nedeljkovic S, Pekkarinen M, Simic BS, Toshima H, Feskens EJM, Hollman PCH, Katan MB. Flavonoid intake and long-term risk of coronary heart disease and cancer in the Seven Countries Study. Arch. Intern. Med. 1995; 155: 381-86.

2. Meyer AS, Heinonen M, Frankel EN. Antioxidant interactions of catechin, cyanidin, caffeic acid, quercetin, and ellagic acid on human LDL oxidation. Food Chem. 1998; 61: 71-75.

3. Agullo G, Gamet-Payrastre L, Manenti S, Viala C, Remesy C, Chap H, Payrastre B. Relationship between flavonoid structure and inhibition of phosphatidylinositol 3-kinase: a comparison with tyrosine kinase and protein kinase $C$ inhibition.Biochem. Pharmacol. 1997; 53:1649-57.

4. Ashida H, Fukuda I, Yamashita T, Kanazawa K. Oxidation and Antioxidants in Organic Chemistry and Biology. FEBSLett. 2000; 476: 213-17.

5. An J, Tzagarakis-Foster C, Scharschmidt TC, Lomri N, Leitman DC. Estrogen receptor beta-selective transcriptional activity and recruitment of coregulators by phytoestrogens. J. Biol. Chem. 2001; 276: 17808-814.

6. Lepley DM, Pelling JC. Induction of p21/WAF1 and G1 cell-cycle arrest by the chemopreventive agent apigenin. Mol. Carcinog. 1997; 19: 74-82.

7. Xagorari A, Papapetropoulos A, Mauromatis A, Economou M, Fotsis T, Roussos C. Luteolon Inhibits an Endotoxin-Stimulated Phosphorylation Cascade and Proinflammatory Cytokine Production in Macrophages. J. Pharmacol. Exp. Ther. 2001; 296: 181-87.

8. Bhatia N, Agarwal R. Detrimental effect of cancer preventive phytochemicals silymarin, genistein and epigallocatechin 3-gallate on epigenetic events in human prostate carcinoma DU145 cells. Prostate. 2001; 46: 98-107.

9. Nagasaka Y, Nakamura K. Spectrofluorimetric and HPLC Determination of Morin in Human Serum. Biochem. Pharamcol. 1998; 56: 1151-55.
10. Kobuchi H, Roy S, Sen CK. H. Nguyen HG, Packer L, Quercetin inhibits inducible ICAM-1 expression in human endothelial cells through the JNK pathway., Am. J. Physiol. 1999; 277: C403-C11.

11. Yang XF, Wang F, Hu SS. Spectroscopic studies on the interaction between troxerutin and bovine serum albumin. Colloid Surf. 2006; B 52: 8-13.

12. Proestos C, Boziaris IS, Nychas GJE, Komaitis M. Analysis of flavonoids and phenolic acids in Greek aromatic plants: Investigation of their antioxidant capacity and antimicrobial activity. Food Chem. 2006; 95: 664-71.

13. Polasek M, Petriska I, Pospisilova M, Jahodar L. Stacking nonaqueous capillary electrophoresis simultaneous determination of salicylic acid, cinnamic acid, ferulic acid and vanilloid. Talanta. 2006; 69: 192-96.

14. Ch L. Chang, Sun SW. Micellar electrokinetic chromatography for separation of a mixture of coptis alkaloids, scute flavonoids, and rhubarb anthraquinones and bianthrones. J. Pharm. Biomed. Anal. 2006; 40: 62-67.

15. Liu JJ, Li SP, WangYT. Optimization for quantitative determination of four flavonoids in Epimedium by capillary zone electrophoresis coupled with diode array detection using central composite design. J. Chromatogr. A 2006; 1103: 344-49.

16. Domenech-Carbo A, Domenech-Carbo, MT Sauri- Peris MC, Electrochemical identification of flavonoid dyes in solid work of art samples by abrasive voltammetry at paraffin-impregnated graphite electrodes. Talanta. 2005; 66: 769-82.

17. FDA Guidance for Industry (2001). Bioanalytical Method Validation, US Department of Health and Human Services, Food and Drug Administration, Centre for Drug Evaluation and Research (CDER), Center for Veterinary Medicine (CVM) May. 